\title{
Ciclos político-orçamentários nos estados brasileiros: um exemplo de problema de delegação na relação principal-agente
}

\author{
Francisco José Sales Rocha' \\ Átila Amaral Brilhante ${ }^{2}$
}

\section{Resumo}

Este artigo demonstra a existência dos ciclos político-orçamentários nos estados brasileiros no período de 1997 a 2009. Ele segue uma versão ligeiramente modificada da teoria dos ciclos políticos oportunistas racionais de Rogoff (1990). Os resultados empíricos obtidos comprovam que os governadores dos estados brasileiros utilizam política fiscal subótima para gerar no eleitor a impressão de que são mais competentes no período imediatamente anterior às eleições. As despesas de investimento têm um aumento relativo (comparado com sua média amostral) de 5,2\% no ano pré-eleitoral e de 11,86\% no ano eleitoral. Como essas despesas são as mais visíveis por parte do eleitor, fica evidente que o governante (agente) as realiza com a intenção de ganhar popularidade e induzir o eleitor (principal) a votar nele. Esse comportamento oportunista do chefe do executivo gera ineficiência na alocação dos recursos e compromete o bem-estar social. Logo, deve ser coibido através dos mecanismos legais, institucionais e mecanismos sociais de controle do poder público (accountability).

Palavras-chave: Ciclos políticos. Principal-agente. Problema de delegação. Controlabilidade.

I Doutor em Economia pela Universidade Federal de Pernambuco (UFPE), Recife, Pernambuco, Brasil e Professor Associado pela Universidade Federal do Ceará (UFC), Fortaleza, Ceará, Brasil. É autor de artigos publicados nas revistas Ethic@ (UFSC) (2010, 201I e 2013), Problemas del Desarrollo (2004) e Economia E Gestão (2002), além de ser autor dos liuros Tópicos Selecionados em Econometria Básica: Teoria e Aplicações (São Paulo, 20II) e Conceitos Básicos de Econometria: Modelo de Regressão Clássico. (São Paulo, 20II). E-mail: salesf@uol.com.br.

2 Doutor em Ciência Política pelo University College London, Londres, Reino Unido e Professor Associado pela Universidade Federal do Ceará (UFC). É autor de artigos publicados na revista Ethic@ (UFSC) (2010, 2011 e 2013), além de ser autor dos livros John Stuart Mill's Liberal-Utilitarian Conception of Democracy: The Centrality of Accountability (Saarbrücken/Deutschland) (2009) e Liberalismo e Ética: A crítica de John Stuart Mill ao Estado minimo (Fortaleza: UFC) (1998). E-mail: atilaabrilhante@gmail.com. 


\section{Introdução}

Neste artigo, busca-se fazer uma verificação empírica, mediante a estimação de dados em painel dinâmico (GMM-DPD), dos ciclos político-orçamentários nos estados brasileiros no período de 1997 a 2009. Logo, este estudo segue de perto a orientaçáo de Rogoff (1990) de que os trabalhos empíricos sobre ciclos políticos deveriam centrar a atenção no poder local (estados e municípios), e de que os testes empíricos sobre a existência de ciclos eleitorais (ou ciclos oportunistas) deveriam ter como foco os instrumentos de política orçamentária, como as despesas públicas em bens, serviços e em investimentos, os quais são mais fáceis de serem manipulados pelos governantes (governador ou prefeito) do que os dados dos agregados macroeconômicos, como renda per capita e taxa de desemprego. Considerando, portanto, que o chefe do executivo estadual possui um maior controle sobre as despesas do que sobre as receitas, e que, dentro das despesas, a rubrica de capital é a que apresenta uma maior possibilidade de controle pelo governador, entáo, essa rubrica terá uma atenção especial nesse trabalho.

Tomando por base a fundamentação teórica da economia política das finanças públicas e o modelo teórico de Rogoff (1990), com pequenas modificações, tem-se por hipótese que a assimetria de informação entre o eleitor (principal) e o eleito (agente) cria condiçóes para que este fomente a geração dos ciclos político-orçamentários ou eleitorais (PERSSON; TABELLINI, 2003). Considera-se, no entanto, que o comportamento oportunista do chefe do executivo gera ineficiência na alocaçáo dos fatores de produçáa porque se utiliza de políticas fiscais subótimas. Tal ineficiência pode ser corrigida por mecanismos de accountability, isto é, mecanismos de controle e responsabilização do poder público que podem contribuir para reduzir as assimetrias de informação entre o eleitor e o eleito. As exigências de cumprimento de leis fundamentadas na filosofia do gasto responsável, como a Lei de Responsabilidade Fiscal, são exemplos de iniciativas que limitam a possibilidade de utilizaçâo de política fiscal subótima nas finanças públicas estaduais.

O motivo do presente trabalho é evidenciar que os ciclos político-orçamentários (ou ciclos eleitorais) geram instabilidade nas despesas de investimento e, consequentemente, acarretam ineficiência na alocaçáo de recursos. A comprovação empírica desses ciclos, por meio da análise econométrica, realça a necessidade da adoçáo de medidas legais, institucionais e de controle social 
que reduzam a possibilidade de utilização de políticas fiscais subótimas pelo governante na condução das finanças públicas estaduais. Os ciclos eleitorais criam, também, dificuldades de ordem macroeconômica, pois dificultam o cumprimento das metas de superávit primário estabelecidas anualmente pelo governo federal.

O painel de dados que serve de amostra para a análise econométrica aqui desenvolvida é constituído pelos dados de 26 estados brasileiros e do Distrito Federal (27 entidades de corte transversal) no período de 1997 a 2009 (13 anos), o que permite cobrir três anos em que houve eleiçáo para governador no Brasil (1998, 2002 e 2006).

Os dados sobre as finanças públicas das entidades de corte (orçamentos estaduais) foram obtidos das estatísticas da Secretaria do Tesouro Nacional (STN). As informaçóes sobre as populaçóes dos estados e o deflator - utilizados para transformar as variáveis do painel em variáveis reais per capita -, foram obtidas no Instituto Brasileiro de Geografia e Estatística (IBGE).

\section{Ciclos Políticos Oportunistas: revisão da literatura}

A literatura econômica apresenta vários modelos que foram desenvolvidos para analisar o papel de variáveis políticas na geraçáo de ciclos econômicos. Esses modelos procuram estudar como o comportamento do governante pode afetar a dinâmica da atividade produtiva de uma unidade geopolítica (país, estado ou município) de acordo com o interesse de reeleiçáo deste. No geral, esse comportamento do governante se pauta na utilizaçáo de políticas monetária ou fiscal subótimas ${ }^{3}$, o que gera ineficiência na alocaçáo dos fatores de produçáo ${ }^{4}$. Dessa forma, esses ciclos econômicos, gerados a partir de tal conduta do governante ${ }^{5}$, são considerados como ciclos políticos oportunistas. Segundo Nakaguma e Bender (2010, p. 4), “[...] considerando-se a restriçáo orçamentária intertemporal do governo, os ciclos eleitorais deveriam ser vistos como prejudiciais à economia, constituindo-se em um desvio desnecessário em relaçáo à trajetória ótima dos gastos e do déficit público.”.

\footnotetext{
3 Considera-se política fiscal ou monetária subótima a política pública que é adotada pelo governante sem preocupação com a alocação eficiente dos fatores de produção, como o trabalho e o capital.

40 que contraria o interesse público.

5 Conduta autointeressada ou oportunista do governante.
} 
Os modelos de ciclos políticos oportunistas podem ser divididos em tradicionais, dentre os quais se destaca o trabalho seminal de Nordhaus (1975), e racionais, cujo trabalho de Rogoff (1990) é tido como principal referência.

A teoria dos ciclos políticos oportunistas tradicionais, à la Nordhaus, considerava que o eleitor náo entendia a dinâmica de funcionamento do processo político-econômico, pois este, em suas decisóes políticas, levava em consideraçáo somente o seu conhecimento sobre o passado e o presente e, também, não possuía conhecimento do processo de manipulaçáo de variáveis e políticas econômicas que ocorrem na estrutura da economia. Essa teoria, portanto, considerava que o eleitor formava as suas expectativas de forma adaptativa ${ }^{6}$ (NORDHAUS, 1975). O governante racional (e oportunista), por sua vez, utilizava política monetária subótima para aumentar a sua probabilidade de reeleiçáo da seguinte forma: no período pré-eleitoral, aumenta-se a oferta monetária para estimular o crescimento econômico e, por conseguinte, reduzir o desemprego. Em decorrência desse fato, o eleitor reage positivamente nas urnas, já que ignora o trade-off inflação-desemprego. Porém, logo após a eleiçáo, usa-se uma política monetária restritiva para reduzir a inflação, levando a uma maior taxa de desemprego.

A teoria dos ciclos políticos oportunistas racionais rejeita a hipótese de que o eleitor forma as suas expectativas de forma adaptativa. Propugna que o eleitor forma as suas expectativas de forma racional e entende perfeitamente a dinâmica de funcionamento do processo político econômico. Isso resulta, no longo prazo, em uma antecipaçáo das açóes e decisóes de políticas do governante por parte do eleitor. Anulando, entáo, a açáo oportunista daquele na geraçáo de ciclos econômicos que beneficiem a sua reeleiçáo. Segundo Fialho (1999), a existência de ciclos políticos oportunistas no curto prazo, enquanto se consolida o processo de aprendizado do eleitor sobre a dinâmica de funcionamento do sistema político-econômico, se torna uma hipótese mais razoável.

No modelo de Rogoff (1990), considera-se que tanto o eleitor quanto o governante formam as suas expectativas de forma racional. Nesse modelo, no entanto, o governante pode agir de forma oportunista ${ }^{7}$, aproveitando uma

6 O eleitor era considerado miope, ou seja, incapaz de aprender com seus erros.

7 Gerando os ciclos político-orçamentários. 
situaçáo temporária de assimetria de informação ${ }^{8}$, e, no período pré-eleitoral, utilizar os instrumentos de política fiscal orçamentária - aumentando as despesas públicas em bens e serviços e em transferências, diminuindo o investimento público, uma vez que este último somente se torna visível no período seguinte $^{9}$-, para estimular o crescimento econômico. Essa conduta do governante levaria a uma resposta positiva nas urnas, mas desequilibraria as contas públicas e também geraria ineficiência na alocação dos fatores de produção.

Considera-se aqui que os ciclos político-orçamentários racionais, à la Rogoff, podem ser analisados assumindo-se que o governante é racional, mas levando-se em conta as limitaçóes da racionalidade do eleitor. Logo, o governante (autointeressado) pode agir de forma oportunista na geraçáo de ciclos econômicos que beneficiem a sua reeleiçáo em detrimento do interesse público. Ou seja, analisando o jogo político à luz da Teoria da Agência (modelo principal-agente), pode-se considerar que o eleitor é o principal e o político eleito/governante é o agente ${ }^{10}$. Portanto, o eleitor (principal), ao eleger determinado político, está delegando a este a tarefa de promover o interesse público. Isto é, o governante (agente) deve procurar adotar políticas ótimas do ponto de vista fiscal (despesas de investimento, tributaçáo etc.) e monetário (juros, redesconto etc.) para garantir ao conjunto da sociedade o melhor resultado em termos de estabilidade monetária, de educaçáo, de saúde, de segurança pública e de infraestrutura. No entanto, considerando que, nessa relaçáo entre o eleitor e o governante, há uma grande assimetria de informaçáo - pois o governante racional é mais bem informado do processo político-econômico do que o eleitor - pode-se dizer que parte das açóes do governante náo sáo observáveis pelo eleitor.

Diante do exposto, considerando a racionalidade limitada do eleitor ${ }^{\prime \prime} \mathrm{e}$ o comportamento autointeressado ${ }^{12}$ do governante racional, tem-se que os

8 "Os eleitores, na maioria das vezes, não são bem informados acerca da competência e desempenho do governo." (Fialho, 1999, p. 139).

9 Esta é a forma como o governante sinaliza a sua competência (Veiga; Veiga, 2004).

10 Para uma análise aprofundada do modelo principal-agente, ver Mas-Collel, Whiston e Gren (1995, p. 477506).

II Segundo o Tribunal Superior Eleitoral, no Brasil, 80\% do eleitorado não possui ensino médio completo, o que contribui para reforçar a assimetria de informações entre os eleitores e os governantes.

12 Assume-se que o princípio do individualismo metodológico norteia a ação do governante. Portanto, o indivíduo age no sentido de maximizar seus próprios objetivos (no caso, a possibilidade de reeleição) em detrimento do interesse público. 
ciclos político- orçamentários se desenvolvem da seguinte forma: o governante no período pré-eleitoral se utiliza da política fiscal, aumentando as despesas ${ }^{13}$ e/ou reduzindo os impostos, para conseguir aumentar a produçáo no estado e, consequentemente, gerar um aumento significativo da demanda por máo de obra ${ }^{14}$. Em decorrência desse fato, o eleitor garante nas urnas a reeleição do governante, pois aquele atribui uma importância significativa ao desempenho da economia no momento de votar. Porém, no período imediatamente após a eleição, o governante vencedor do pleito se utiliza da política fiscal, reduçáo das despesas e/ou aumento de impostos, para reduzir o nível da atividade produtiva do estado, o que por sua vez gera uma reduçáo na demanda por mão de obra para combater o desequilíbrio fiscal.

Segundo Rogoff (1990), os ciclos político-orçamentários permitem ao eleitor identificar e eleger o candidato de maior competência. Mas esses ciclos são equilíbrios ineficientes, pois o governante age de forma oportunista na geração do ciclo econômico no estado e utiliza política fiscal subótima. ${ }^{15}$ Isso interfere na alocaçáo eficiente dos fatores de produçáo e na estabilidade das finanças estaduais. A instabilidade nas despesas de investimentos do governo resulta em superfaturamento e má qualidade das obras realizadas, o que pode comprometer, de forma significativa, o interesse público. Por sua vez, a instabilidade nas finanças públicas estaduais pode levar a dificuldades em se cumprir as metas anuais de superávit primário, o que contribui para aumentar a instabilidade nas despesas de investimento do governo. A utilizaçáo dessas despesas para proporcionar um "boom" econômico e desequilibrar as finanças estaduais gera a necessidade de contingenciar despesas de investimentos em infraestrutura no início da gestáo seguinte.

A realidade da alocaçáo ineficiente de recursos por parte dos governos configura uma situaçáo típica de Problema de Delegação (ARAÚJO; SANCHEZ, 2005). Ou seja, admitindo que o governante (agente) recebe uma delegaçáo do eleitor (principal) para agir em seu nome em busca do bem comum e que há assimetria de informação no processo político-econômico,

13 Principalmente aumentando as despesas de investimentos que são mais visíveis pelo eleitor.

14 Esta é a forma que o governante utiliza para sinalizar maior competência.

15 Esse comportamento do governante caracteriza uma situação de risco moral ou moral hazard (FERREIRA; BUGARIN, 2007) 
o eleitor, então, que possui racionalidade limitada, está em desvantagem com relação ao governante, que tem racionalidade mais abrangente. Logo, o governante, agindo de forma autointeressada utiliza a dinâmica dos ciclos político-orçamentários para garantir a sua reeleiçáo. Em síntese, o eleitor delega ao governante a tarefa de utilizar a política fiscal de forma ótima para alcançar o bem comum, mas essa tarefa não é cumprida, pois o governante age de forma oportunista para obter ganhos privados, isto é, reeleger-se. O comportamento oportunista do governante na condução das finanças públicas estaduais deve ser combatido pelo eleitor porque é prejudicial à sociedade.

Araújo e Sanchez (2005, p. 160) consideram que

[o] controle sobre a burocracia estatal dependerá da forma como são construídos, em cada sociedade, arranjos institucionais que limitem e constranjam os possíveis comportamentos oportunistas dos agentes, pois são as instituições que organizam essas relações.

Portanto, para tentar resolver o Problema de Delegaçáo supracitado e, por conseguinte, reduzir as ineficiências na alocaçáo de recursos geradas na dinâmica de um ciclo oportunista, faz-se necessário estabelecer algumas medidas legais e Mecanismos de Controle que reduzam a possibilidade de utilizaçáo de política fiscal subótima pelo governante na condução das finanças públicas estaduais.

No Brasil, há leis que, mesmo que não tenham sido criadas para combater as ineficiências geradas em um ciclo oportunista, podem ser consideradas como exemplo de medidas legais que contribuem para resolver o Problema de Delegação ora em análise. A Constituição Federal de 1988, legislando sobre a execuçáo orçamentária, estabelece, em seu art. 167, a proibiçáo de realizar, em cada exercício, operaçóes de crédito que excedam o montante das despesas de capital, salvo lei específica autorizada. A Lei no. 9.504, de 30 de setembro de 1997, conhecida como lei Eleitoral, próbe aos agentes públicos condutas que afetem a igualdade de oportunidades entre candidatos nos pleitos eleitorais; destaca-se a proibição da realização de transferência voluntária nos três meses que antecedem o pleito. A Lei de Responsabilidade Fiscal (LRF), Lei complementar $\mathrm{n}^{\circ} 101$, de 4 de maio de 2000 , dispóe sobre a tributaçáo e o orçamento e estabelece normas gerais de finanças públicas a serem observadas pelos três níveis de poder: nessa Lei, os entes federados passam a ter um limite máximo para a sua dívida e, por conseguinte, restriçôes para a realizaçáo de novas operaçóes de crédito, principalmente em anos eleitorais. 
As sociedades devem criar e aperfeiçoar mecanismos de controle capazes de resolver o Problema de Delegação resultante da utilização de política fiscal para gerar ciclos oportunistas. Tais mecanismos pressupóem um sistema democrático que garanta as liberdades de opiniáo, associação, informaçáo e a imprensa livre (O'DONNEL, 1998), essencial para tornar os eleitores mais informados e reduzir a assimetria de informaçáo entre eles e os governantes. ${ }^{16}$ As eleiçóes são, indubitavelmente, instâncias de controle da sociedade em relaçáo aos governantes. Há, contudo, além delas, um vasto leque de mecanismos de controlabidade (accountability) destinados a por limites e demandar esclarecimentos dos poderes instituídos. A accountability vertical diz respeito aos mecanismos de controle da sociedade em relaçáo ao governante, e a accoutability horizontal relaciona-se ao controle do governante pelas instituiçóes do próprio estado.

A questão da accountability vertical, como mecanismo de controle social para coibir a açáo de governantes na geração de ciclos oportunistas, está diretamente relacionada às ideias que norteiam os estudos que analisam os ciclos políticos com base nos modelos de controle eleitoral ${ }^{17}$. Esses modelos partem da hipótese de que os governantes são oportunistas e consideram as eleiçóes como um instrumento de controle à disposiçáo dos eleitores. Dessa forma, a causa, em parte, dos ciclos eleitorais seria a incapacidade do eleitorado de identificar e punir manipulaçóes fiscais oportunistas dos governantes, o que caracterizaria um monitoramento político (accountability vertical) inadequado do eleitor (NAKAGUMA; BENDER, 2010). Entâo, definindo-se moral hazard como "[...] a escolha de uma política fiscal subótima [...]" ( FERREIRA E BUGARIN, 2007, p. 294), pode-se, portanto, dizer que, nos modelos de controle eleitoral, ocorre um problema de moral hazard na relação principal(eleitor)-Agente(governante) ${ }^{18}$. Como foi dito anteriormente, esse problema pode ter seus efeitos negativos sobre a eficiência alocativa, mas podem ser mitigados caso o eleitor se torne mais bem informado do processo político-econômico e, em razáo disso, puna os governantes oportunistas.

16 Com a obtenção de informações mais compativeis com a realidade.

17 Para uma melhor compreensão de modelos de controle eleitoral, ver Besley e Case (1995).

18 Para uma análise formal do problema de moral hazard na relação principal-agente, ver Mas-Collel. Whiston e Gren (1995, p. 478-488). 
A accountability horizontal, no entanto, é a forma de se controlar a ação oportunista do governante por meio dos mecanismos de limitaçáo e controle que se formam na estrutura institucional do Estado, como o controle mútuo entre os três poderes, isto é, o Executivo, o Legislativo e o Judiciário. Porém, outras instituiçóes do sistema político também podem fazer parte desse mecanismo de controle. No Brasil, por exemplo, o Ministério Público e os Tribunais de Contas exercem um papel importante nesse tipo de controle, pois as açóes dos mesmos podem, a partir da análise das contas públicas, auxiliar na identificaçáo de possíveis condutas oportunistas de governantes que conseguem a reeleiçáo, utilizando política fiscal subótima, em detrimento do interesse público. No entanto, para que esses mecanismos de controle apresentem os resultados esperados, faz-se necessário "[...] a existência de instituiçóes, agências e órgão estatais detentores de poder, legal e de fato, de realizar açóes que vão desde a supervisão de rotina até sançóes legais contra atos delituosos de seus congêneres do Estado." (ARAÚJO; SANCHEZ, 2005, p. 142).

\section{Evidências empíricas de ciclo político no Brasil}

A seguir, seráo apresentados os resultados de alguns trabalhos realizados no Brasil que analisam os ciclos políticos, tomando por base as unidades subnacionais, municípios e estados, e utilizam os instrumentos de política orçamentária, como receita, transferências, despesas de capital e de investimento, para realizar os testes empíricos (análise econométrica) sobre a existência de ciclos eleitorais (ou oportunistas).

Ferreira e Bugarin (2007), utilizando a análise de dados em painel, testam a hipótese da existência da motivação partidária, ao nível dos municípios brasileiros, no período de 1999 a 2004. Considera-se a motivação partidária como uma variável binária que assume o valor unitário quando há alinhamento político do prefeito com o governador, o Presidente da República ou com as coligaçóes que os elegeram, e zero caso contrário. Logo, testa-se a hipótese de que as transferências voluntárias são maiores para os municípios em que ocorrem tais alinhamentos políticos. Seus resultados mostram uma correlaçáo positiva entre o alinhamento político de prefeitos com as coligaçóes que elegeram os governadores e as transferências voluntárias recebidas pelos municípios e, também, evidenciam uma correlação positiva entre o alinhamento político (ser do mesmo partido) de prefeitos com o Presidente da República 
e as transferências voluntárias. Diante dessas evidências empíricas, os autores (FERREIRA; BUGARIN, 2007) sugerem um modelo estendido para se estudar os ciclos político-orçamentários, em federaçóes fiscais, como a brasileira, levando-se em consideraçáo as transferências politicamente motivadas.

Sakurai (2005), ao utilizar análise econométrica de dados em painel e modelos de variável dependente binária (modelos probit e logit), testa a hipótese da racionalidade dos eleitores em municípios paulistas selecionados no período de 1989 a 2001. Seus resultados mostram, para a análise de dados em painel, que, em anos eleitorais, os governantes (ou partidos) que conseguem êxito na reeleiçáo gastam, em média, $\mathrm{R} \$ 14,62$ per capita a mais no total do orçamento municipal. Esse fato corrobora a hipótese de que os prefeitos que têm sucesso na reeleiçáo sáo os que aumentam as despesas orçamentárias em anos eleitorais. Para a análise de variável dependente binária por meio do modelo probit (modelo de variável dependente binária cuja estrutura formal toma por base a distribuiçáo normal), os resultados apresentam evidências de impulsos positivos em anos eleitorais na despesa orçamentária dos municípios selecionados. O autor (2005) considera que as evidências empíricas, para a amostra estudada, configuram um resultado que descaracteriza a hipótese de racionalidade dos eleitores, nos termos propostos pela teoria oportunista racional.

Sakurai e Menezes Filho (2008), a partir de uma análise econométrica de dados em painel via modelo logit (modelo de variável dependente binária cuja estrutura formal toma por base a distribuiçáo logística) com efeitos fixos, testam a influência das despesas públicas sobre a probabilidade de reeleiçáo de prefeitos em municípios selecionados do Brasil no período de 1988 a 2003. Os resultados obtidos das regressóes estimadas sugerem que aumentar as despesas totais durante todo um mandato de um prefeito é visto de forma favorável pelo eleitor, o que se traduz em uma alta probabilidade de reeleição do governante. Os resultados mostram, também, que as pretensóes eleitorais dos prefeitos brasileiros são afetadas positivamente tanto pelos aumentos das despesas de capital, nos três anos anteriores a uma eleição, quanto pelos desvios das despesas correntes em anos de eleiçáo (relativos aos anos anteriores). Os autores (2008, p. 312) concluem que os eleitores brasileiros sáo receptivos ao investimento de capital e também às manipulaçóes fiscais em anos eleitorais.

Nakaguma e Bender (2010) apresentam uma metodologia que decompóe os ciclos eleitorais e testam a hipótese de que a elevação dos gastos públicos 
pode ser percebida pelos eleitores tanto como uma tentativa sinalizar competência quanto uma evidência de oportunismo por parte dos governantes. Os autores, procuram testar essa hipótese (percepçáo do eleitor sobre a açáo do governante) via regressáo de dados em painel. Ou seja, por análise de regressáo realizada com base em um agrupamento de dados amostrais dos 26 estados brasileiros mais o Distrito Federal no período de 1986 a 2004. O trabalho é estruturado em duas etapas. Na primeira, testa-se a existência dos ciclos eleitorais nos estados brasileiros no período em questáo, baseando-se na estimaçáo de modelos que têm como variável dependente (variável cujo valor médio é estimado a partir dos valores amostrais das variáveis explicativas) uma variável fiscal, como as receitas, as transferências ou as despesas, e como variáveis explicativas as variáveis políticas (como o índice de fragmentação das preferências, que busca capturar o ambiente político vigente nos estados; e uma variável indicando se o governador pertence ou náo ao partido do Presidente da República. Busca-se saber se há um efeito positivo dessa variável sobre a reeleição dos governadores) e eleitorais (variáveis binárias para os anos pré-eleitoral, eleitoral e pós-eleitoral), as variáveis de controle (crescimento dos Produtos Internos Brutos estadual e nacional e taxa de inflaçáo), um efeito fixo estadual não observado (esse efeito é utilizado para evitar que se cometa viés de variáveis explicativas omitidas que variam entre os estados, mas que são constantes ao longo do tempo. Esse tipo de viés compromete a qualidade do valor médio estimado da variável dependente, portanto deve ser corrigido com a utilizaçáo dos efeitos fixos estaduais) e um termo de erro aleatório ruído branco (erros não correlacionados com média zero e variância constante).

Segundo os autores (NAKAGUMA; BENDER, 2010), os resultados fiscais estimados (para as receitas, as transferências ou as despesas) podem, sob a ótica dos eleitores, ser divididos em três componentes: uma parcela esperada explicada pelas variáveis de controle e pelo efeito fixo estadual, que náo possuem qualquer influência do governante; uma parcela esperada e devida exclusivamente ao fato de estar-se em um ano eleitoral, sendo esta parcela explicada pelas variáveis políticas e eleitorais - esta parcela é utilizada como proxie $e^{19}$ para o nível de oportunismo do governante na segunda parte da verificaçáo empírica do

19 Proxies: valores estimados na primeira parte do estudo de regressão que representam os dados amostrais não observados de uma variável que será utilizada na segunda parte do estudo. 
trabalho -; e uma parcela residual (obtida nos anos eleitorais) náo explicada pelas variáveis do modelo. Essa parcela, por sua vez, é utilizada como proxie da competência dos governantes na segunda parte do estudo, como será mostrado a seguir.

$\mathrm{Na}$ segunda etapa, estima-se um modelo que tem como variável dependente o percentual de votos obtidos em primeiro turno pelo candidato do governo e como variáveis explicativas a variaçáo percentual do resultado fiscal previsto no ano eleitoral, o oportunismo, a competência dos governantes - estas duas últimas variáveis entram no modelo de acordo com o que foi estabelecido no parágrafo anterior como sendo suas proxies -, as variáveis de controle, um efeito fixo estadual e um termo de erro ruído branco. Os resultados mostram que os eleitores recompensam a parcela oportunista dos ciclos, tanto nas receitas quanto nas despesas orçamentárias. Nakaguma e Bender (2010) consideram, portanto, que a falta de um controle político adequado pelo eleitorado ${ }^{20}$ induz, pelo menos em parte, os ciclos eleitorais. Com relaçáo à parcela da competência, os resultados mostraram que o processo de sinalização de competência se dá, principalmente, via receitas orçamentárias.

No trabalho ora em elaboração, busca-se fazer não só uma análise positiva da existência de ciclos oportunistas, o que é feito com propriedade nos trabalhos supracitados realizados na literatura brasileira, mas também uma análise normativa, ao se apontar o uso da accountability vertical e horizontal como instrumento que pode ser utilizado para mitigar os efeitos negativos da açáo oportunista de governantes sobre a eficiência econômica e, consequentemente, sobre o bem-estar social nos estados brasileiros.

\section{Especificação do modelo econométrico}

A mensuração do impacto de fatores eleitorais nas finanças públicas dos estados brasileiros será feita ao se testar, com base em estimaçáo de modelo econométrico de dados em painel dinâmico, as hipóteses da existência de ciclos político-orçamentários no âmbito das despesas orçamentárias estaduais.

Dessa forma, será estimado um primeiro modelo cuja variável dependente é a Despesa Total (DESPTOT). Tem-se por hipótese que essa variável

20 Accountability vertical. 
apresenta baixa margem de manobra oportunista, dado o peso da folha salarial em sua composiçáo. Portanto, considera-se que as Despesas de Capital (DESPK) e, dentro dessas, a rubrica Despesas de Investimento (DESPINV) estáo mais sujeitas às manipulaçóes oportunistas do governante. Logo, é factível supor que a evidência empírica de ciclos político-orçamentários seja maior nesses dois últimos tipos de despesas. Assim, no segundo modelo empírico a ser testado, tem-se como variável dependente DESPK e, no terceiro modelo, DESPINV. Essas variáveis, assim como as demais utilizadas no trabalho, seráo apresentadas em termos reais per capita. Ou seja, para cada estado, os valores nominais dessas variáveis foram divididos pelo Índice de Preço ao Consumidor Amplo (IPCA) para o ano base de 1997 e, depois, pela sua população total.

Nos modelos supracitados seráo usadas as seguintes variáveis explicativas:

1. Valores defasados da variável dependente, de forma a se considerar a componente autorregressiva da série temporal;

2. Transferências Totais (TRANSFTOT) que o estado $i$ recebe no ano $t$ - dada a importância dessa variável na receita dos estados, espera-se que esta tenha influência positiva e significativa sobre DESPTOT no primeiro modelo - e Transferências de capital (TRANSFK) que o estado $i$ recebe no ano $t$-dada a importância dessa variável na receita dos estados, espera-se que maiores transferências permitam maiores despesas de capital (DESPK) e de investimento (DESPINV), no segundo e terceiro modelo, respectivamente;

3. Ano Pré-Eleitoral (ANOPRE) é uma variável binária que assume o valor um em ano anterior à eleiçáo para governador e zero caso contrário. Com essa variável, testa-se a hipótese de que, em ano pré-eleitoral, a despesa total, de capital e de investimento, são maiores, comparativamente à média amostral destas. Logo, espera-se um sinal positivo e significante para a estimativa da variável em questáo, principalmente no terceiro modelo;

4. Ano Eleitoral (ANOE) é uma variável binária que assume o valor um em ano de eleição para governador e zero caso contrário. Com essa variável, testa-se a hipótese de que, em ano eleitoral, a despesa total, de capital e de investimento, são maiores, comparativamente à média amostral destas. Logo, espera-se um sinal positivo e significante para a estimativa da variável em questáo (VEIGA; VEIGA, 2004). 
O modelo econométrico de Dados em Painel Dinâmico (DPD), utilizado neste artigo, toma por base Arellano e Bond (1991), autores que desenvolveram um estimador de Método de Momentos Generalizados (Generalized Method of Moments-GMM), cuja equaçáo dinâmica é dada por:

$$
\begin{aligned}
& \Delta y_{i t}=\Delta \sum_{j=1}^{p} \alpha_{j} y_{i, t-j}+\Delta X^{\prime}{ }_{t} \beta+\Delta \varepsilon_{i} \\
& i=1, \ldots, N \quad t=1, \ldots, T
\end{aligned}
$$

Sendo $y_{i t}$ : variável dependente, isto é, a Despesa Total, a Despesa de capital e a Despesa de Investimento, nos modelos 1, 2 e 3, respectivamente; $P$ : número de valores defasados da variável dependente; $X_{i t}^{\prime}$ : vetor de variáveis explicativas, ou seja, valores defasados da variável dependente, as Transferências Totais e os anos pré-eleitoral e eleitoral, no modelo 1, e valores defasados da variável dependente, as Transferência de Capital e os anos pré-eleitoral e eleitoral, nos modelos 2 e 3 , respectivamente; $\beta$ : vetor de parâmetros a ser estimado - esse vetor fornece as estimativas geradas para os parâmetros do modelo, o que permite analisar se as estimativas obtidas para as variáveis ano pré-eleitoral e ano eleitoral confirmam ou não a hipótese de ciclos oportunistas -; $\varepsilon_{i t}$ : erro aleatório, composto por outras variáveis, além das variáveis explicativas diretamente utilizadas no modelo, que afetam as variáveis dependentes dos modelos estimados.

O modelo acima pode ser estimado por variáveis instrumentais (VI). Isto é, o processo de estimação é realizado com a utilização de variáveis adicionais, ou instrumentos, que isolam os efeitos de variáveis explicativas náo correlacionadas com o erro aleatório, o que gera estimaçóes consistentes com os parâmetros do modelo. Esse processo é aplicado, na prática, via o método de estimação GMM-DPD (Generalizado Método dos Momentos-Dados em Painel Dinâmico $)^{21}$. Os instrumentos válidos são: os níveis da variável dependente e seus valores defasados $\left(\mathrm{y}_{\mathrm{i} 1}, \ldots, \mathrm{y}_{\mathrm{it}-2}\right)$; os níveis das variáveis endógenas e seus valores defasados $\left(\mathrm{x}_{\mathrm{i} 1}, \ldots, \mathrm{x}_{\mathrm{it}-2}\right)$; os níveis das variáveis exógenas e seus valores defasados $\left(\mathrm{x}_{\mathrm{i} 1}, . ., \mathrm{x}_{\mathrm{it}-1}\right)$; ou as primeiras diferenças das variáveis exógenas.

21 Ver Veiga e Veiga (2004, p. 10). 


\section{Resultados empíricos}

A tabela 1 apresenta as estatísticas descritivas das variáveis utilizadas nos modelos econométricos descritos na seçáo anterior. Ou seja, a estatística Média (Amostral), principalmente para as variáveis Despesa e Transferências, é apresentada como um valor de referência, dado que se trata de uma medida de tendência central, para que se possa comparar os desvios que ocorrem dessas variáveis com relaçáo às suas respectivas médias nos anos pré-eleitoral e eleitoral. A comparação desses desvios, com relação às suas médias, ajuda no entendimento de como se processam os ciclos oportunistas nos estados brasileiros no período em análise. As estatísticas Mínimo e Máximo mostram o menor e o maior valor que as variáveis em questáo assumem na amostra utilizada no estudo. O Desvio-Padrão, por sua vez, expressa a dispersão absoluta dos valores amostrais. Observa-se, portanto, que a despesa total média é de $\mathrm{R} \$ 915,44$; a despesa de capital média, de $\mathrm{R} \$ 157,53$; e a despesa de investimento média, de $\mathrm{R} \$ 99,95$. No que diz respeito às transferências, tem-se que as médias das transferências totais e de capital são, respectivamente, $R \$ 395,01$ e $R \$ 17,87$.

Tabela I - Estatísticas Descritivas

\begin{tabular}{lccccc}
\hline Variáveis & No Obs. & Média & Mínimo & Máximo & Desvio-Padrão \\
\hline $\begin{array}{l}\text { Despesa Total } \\
\text { (DESPTOT) }\end{array}$ & 351 & 915,44 & 0000,00 & 3009,00 & 442,44 \\
\hline $\begin{array}{l}\text { Despesas de Capital } \\
\text { (DESPK) }\end{array}$ & 351 & 157,53 & 19,00 & 762,00 & 110,06 \\
\hline $\begin{array}{l}\text { Despesas de Investimento } \\
\text { (DESPINV) }\end{array}$ & 351 & 99,95 & 5,00 & 699,00 & 94,44 \\
\hline $\begin{array}{l}\text { Transferências Totais } \\
\text { (TRANSFTOT) }\end{array}$ & 351 & 395,01 & 71,51 & 1944,64 & 376,24 \\
\hline $\begin{array}{l}\text { Transferências de Capital } \\
\text { (TRANSFK) }\end{array}$ & 351 & 17,87 & 0,00 & 262,00 & 32,36 \\
\hline $\begin{array}{l}\text { Ano Pré-Eleitoral } \\
\text { (ANOPRE) }\end{array}$ & 351 & 0,23 & 0,00 & 1,00 & 0,42 \\
\hline $\begin{array}{l}\text { Ano Eleitoral } \\
\text { (ANOE) }\end{array}$ & 351 & 0,23 & 0,00 & 1,00 & 0,42 \\
\hline
\end{tabular}

Fonte: os autores, com base nas informações contidas nas estatísticas da Secretaria do Tesouro Nacional (STN) e do Instituto Brasileiro de Geografia e Estatística (IBGE).

Nota: Os valores das variáveis de despesas e de transferências estão em reais, a preços de 1997, por habitante. 
$\mathrm{Na}$ tabela 2, sáo apresentados os resultados das regressóes estimadas para os três modelos descritos na seçáo anterior, usando GMM-DPD (Generalizado Método dos Momentos-Dados de Painel Dinâmico). As estatísticas-t são expostas entre parênteses, e a significância estatística é assinalada com asteriscos. As duas últimas linhas da tabela apresentam, respectivamente, o número de observaçóes e o número de estados no modelo estimado.

Tabela 2 - Ciclos político-orçamentários
nas finanças dos estados brasileiros

\begin{tabular}{|c|c|c|c|}
\hline & $\begin{array}{c}\text { DESPTOT } \\
(\text { MODELO I) }\end{array}$ & $\begin{array}{c}\text { DESPK } \\
(\text { MODELO 2) }\end{array}$ & $\begin{array}{c}\text { DESPINV } \\
\text { (MODELO 3) }\end{array}$ \\
\hline \multirow{3}{*}{ DESPTOT (-1) } & 0,3778 & & \\
\hline & $(8,35)^{\star * \star}$ & ------------- & -------------- \\
\hline & & 0,3575 & \\
\hline \multirow[t]{2}{*}{ DESPK $(-1)$} & ----------- & $(65,76)^{* * *}$ & ------------- \\
\hline & & & 0,3260 \\
\hline \multirow[t]{2}{*}{ DESPINV $(-I)$} & ------------- & ------------ & $(60,19)^{* * *}$ \\
\hline & $0,97 \mid 3$ & & \\
\hline \multirow[t]{2}{*}{ TRANSFTOT } & $(279,22)^{\star \star \star}$ & ------------- & ------------- \\
\hline & & $1,058 \mid$ & $|, 09|$ \\
\hline \multirow[t]{2}{*}{ TRANSFK } & ------------- & $(15,45)^{* * *}$ & $(13,73)^{* * *}$ \\
\hline & $-22,0561$ & $-3,6626$ & 5,2011 \\
\hline \multirow[t]{2}{*}{ ANOPRE } & $(-7,57)^{\star \star \star}$ & $(-3,46)^{\star \star \star}$ & $(23,24)^{\star \star \star}$ \\
\hline & $-11,4279$ & 22,6601 & 11,8535 \\
\hline ANOE & $(-3,76)^{\star \star \star}$ & $(20,05)^{* * *}$ & $(12,04)^{* * *}$ \\
\hline$N^{\circ}$ de OBS. & 297 & 297 & 297 \\
\hline$N^{\circ}$ de ESTADOS & 27 & 27 & 27 \\
\hline
\end{tabular}

Fonte: os autores, com base nos dados da Secretaria do Tesouro Nacional (STN) e do Instituto Brasileiro de Geografia e Estatística (IBGE).

Notas: - Estimação dos Modelos via GMM-DPD (Generalizado Método dos Momentos-Dados em Painel Dinâmico), com a utilização do programa EViews; - As Estatísticas-t, entre parênteses, testa a significância estatística individual dos parâmetros do modelo em estudo, dado certo Nível de Significância; - O Nível de significância para que se rejeite a hipótese nula, de que um dado parâmetro do modelo não é estatisticamente significante, é: ***, I\%; **, $5 \% ; e^{*}, 10 \%$. 
O valor defasado, em um período da variável dependente, é estatisticamente significativo a $1 \%$ em todos os modelos estimados, o que mostra a importância da componente autorregressiva da série temporal na especificaçáo dos modelos em estudo. Os coeficientes estimados das transferências totais (TRANSFTOT) e de capital (TRANSFK) têm sinais positivos e são estatisticamente significativos, a 1\%, em todos os modelos. Esse resultado está de acordo com a teoria, pois mostra que: quanto maiores forem as transferências que um estado recebe em um dado ano, maiores serão as suas despesas.

No Modelo 1, que tem como variável dependente a despesa total (DESPTOT), não há evidências de ciclos oportunistas, pois as variáveis explicativas ano pré-eleitoral (ANOPRE) e ano eleitoral (ANOE), ambas estatisticamente significativas a $1 \%$, apresentam sinal negativo, o que significa que tanto no ano pré-eleitoral quanto no ano eleitoral a despesa total é menor do que sua média amostral. Esse resultado, a princípio, não está coerente com a teoria dos ciclos político-orçamentários. Porém, como foi explicitado na seçáo anterior, a despesa total apresenta baixa margem de manobra oportunista, dado o peso da folha salarial em sua composição. Logo, considera-se que as manipulaçóes oportunistas do governante sejam mais factíveis de ocorrer sobre as variáveis dependentes despesa de capital (DESPK), Modelo 2, e despesas de investimento (DESPINV), Modelo 3.

No Modelo 2, que tem como variável dependente a despesa de capital (DESPK), há evidências de ciclo político oportunista, pois as variáveis explicativas ANOPRE e ANOE são estatisticamente significativas a 1\%. A variável ANOPRE apresenta sinal negativo, indicando que, no ano pré-eleitoral, as despesas de capital sáo contingenciadas em torno de 2,3\%, comparativamente à sua média amostral; e a variável ANOE apresenta sinal positivo, mostrando que, no ano de eleiçấo, mantendo-se tudo mais constante, as despesas de capital aumentam cerca de $\mathrm{R} \$ 22,66$, a preço de 1997 , por habitante, um aumento relativo (comparando-se com a sua média amostral de $\mathrm{R} \$ 157,53$ ) de 14,48\%.

No Modelo 3, que tem como variável dependente a despesa de investimento (DESPINV), há forte evidência empírica de ciclo político oportunista nas finanças dos estados brasileiros, o que se explica pela maior margem de manobra eleitoreira a que essa variável está sujeita. Os resultados mostram que, tudo mais constante, as despesas de investimento têm um aumento, no ano pré-eleitoral, de $\mathrm{R} \$ 5,20$, o que representa, em termos relativos (comparado 
com sua média amostral de $\mathrm{R} \$ 99,95)$, um aumento de 5,2\%; e um aumento, no ano eleitoral, de $\mathrm{R} \$ 11,85$, o que representa, em termos relativos, um aumento de $11,86 \%$. Ou seja, como alguns investimentos levam alguns meses para serem concluídos, e as obras se tornam visíveis para o eleitor (principal), o governante (agente) já começa a aumentar as despesas de investimento no ano pré-eleitoral, sendo essas despesas ainda mais ampliadas no ano de eleição.

\section{Conclusão}

Os resultados empíricos comprovam a existência de ciclos político-orçamentários (ciclos eleitorais) nos estados brasileiros no período em análise. $\mathrm{Ou}$ seja, os governadores dos estados brasileiros, em consonância com os ciclos oportunistas racionais de Rogoff (1990), utilizam política fiscal subótima para dar ao eleitor a impressáo de que são competentes no período imediatamente anterior às eleiçóes. Há evidências empíricas fortes de que, tudo mais constante, as despesas de investimento têm um aumento relativo (comparado com sua média amostral) de 5,2\% no ano pré-eleitoral e de 11,86\% no ano eleitoral, respectivamente. Como essas despesas são as mais visíveis por parte do eleitor, o governante (agente) as realiza com a notória intençáo de ganhar popularidade e induzir o eleitor (principal) a votar nele. Admitindo-se que prevalece, no eleitorado, a intençáo de delegar aos políticos poderes para a promoçáo do interesse público, seria apropriado a eles buscar a adoçáo de políticas ótimas do ponto de vista fiscal. Logo, uma adequada delegaçáo de poder supóe a necessidade da implementaçáo de mecanismos de controle social e legal para impedir a condução da execução orçamentária com base no comportamento oportunista dos governantes.

As medidas legais a que foram feitas referências no corpo do texto são de grande importância para disciplinar o uso do dinheiro público, mas náo podem ser dissociadas dos mecanismos de accountability vertical e horizontal. Eles permitem que o eleitor se torne mais bem informado e faça uma escolha eleitoral mais refletida. E mais: permitem que se exerça um controle mais permanente sobre as açóes do poder público tanto a partir de pressóes de fora do estado como também de esforços para cooperar com os órgáos públicos de controle. É necessário que o instituto jurídico de delegaçáo de poder esteja associado a toda uma sistemática de controle do poder delegado sob pena de se inviabilizar a promoçáo do bem estar social. 


\section{Referências}

ARAÚJO, M.; SANCHEZ, O. A. A Corrupção e os Controles Internos do Estado. Lua Nova, v. 65 , p. $137-173,2005$.

ARRETCHE, M.; RODDEN, J. Política Distributiva na Federação: Estratégias Eleitorais, Barganhas Legislativas e Coalizóes de Governo. Dados, v. 47, n. 3, p. 549-576, 2004.

BALTAGI, B. H. Econometric Analysis of Panel Data. John Wiley \& Sons, 2008.

BESLEY, T.; CASE, A. Incumbent behavior: vote-seeking, tax-setting and yardstick competition. American Economic Review, v. 85, p. 25-45, 1995.

CAMPOS, A. M. Accountability: Quando poderemos Traduzi-la para o Português? Revista de Administraçáo Pública, Rio de Janeiro, FGV , v. 24, n. 2, p. 30-50, fev/abril, 1990.

COSSÍO, F. A. B. O Comportamento Fiscal dos Estados Brasileiros e seus Determinantes Políticos. Anais do XXVIII Encontro da ANPEC, Campinas, São Paulo, 2000. CD-ROM.

FERREIRA. I. F. S.; BUGARIN, M. S. Transferências Voluntárias e Ciclo Político-Orçamentário no Federalismo Fiscal Brasileiro. RBE, v. 61, n. 3, p. 271-300, 2007.

FIALHO, T. M. M. Ciclos Políticos: uma Resenha. Revista de Economia Política, Sáo Paulo, v. 19, n. 2, p. 131-149, 1999.

MAS-COLLEL, A.; WHISTON, M.; GREN, J. R. Microeconomic Theory. New York: Oxford University Press, 1995.

MELO, M. Governance e Reforma do Estado: O paradigma agente x principal. Revista do Serviço público, Brasília, v. 120, ENAP, 1996.

MENEGUIN, F. B.; BUGARIN, M. S. Reeleiçáo e Política Fiscal: um Estudo dos Efeitos da Reeleiçáo nos Gastos Públicos. Economia Aplicada, v. 5, n.3, p. 600-22, 2001.

NAKAGUMA, M. Y.; BENDER, S. Ciclos Políticos e Resultados Eleitorais: Um estudo Sobre o Comportamento do Eleitorado Brasileiro. RBE, v. 64, n. 1, p. 3-24, 2010.

O’DONNELL, G. Accountability Horizontal e Novas poliarquias. Lua Nova, v. 44, p. 27-54, 1998. PERSON, T.; TABEllini, G. Do Electoral Cycles Difer Across Political Systems? IGIER, Working papers, v. 232, 2003.

ROGOFF, K. Equilibrium Political Budget Cycles. The American Economic Review, v. 80, p. 21-36, 1990. 
SAKURAI, S. N. Testando a Hipótese de Ciclos Eleitorais racionais nas Eleiçóes dos Municípios paulistas. Est. Econ., Sáo Paulo, v. 35, n. 2, p. 297-315, 2005.

.; MENEZES FILHO, N. A. Fiscal Policy and Reelection in Brazilian Municipalities.

Public Choice, v. 137, p. 301-314, 2008.

TUFTE, E. Political Control of the Economy. Princeton: Princeton University Press, 1978.

VEIGA, L. G.; VEIGA, F. J. Ciclos Político-Econômicos nos Municípios Portugueses. II Conferência do Banco de Portugal. Desenvolvimento Económico Português no Espaço Europeu. Universidade do Minho, 2004.

WOOLDRIDGE, J. M. Econometric analysis of cross section and panel data. Cambridge: MIT press, 2002.

\section{Political-budgetary cycles in Brazilian states: an example of delegation problem in the principal-agent relationship}

\section{Abstract}

This article demonstrates the existence of political-budgetary cicles in Brazilian states from 1997 to 2009. It follows a slightly modified version of Rogoff's theory of the rational opportunistic political cicle (1990). The empirical results obtained prove that the governors of Brazilian states use suboptimal fiscal policy to lead the electors to believe that they are competent in the period immediately before the elections. The investment expenditure has a relative increase of $5,2 \%$ in the pre-electoral year and $11,86 \%$ the electoral year when compared to the sample average. As this type of expenditure is more visible to the electorate, it is evident that the governor (agent) uses it to gain popularity and induce electors to vote for him. Such an opportunistic behavior from the state chief executiv (governor) generates inefficiency in the allocation of resources and compromises the wellbeing of society. Therefore, it should be inhibit by means of legal, institutional and social mechanisms destined to control the public power (accountability).

Keywords: Political Cicles. Principal-agent. Delegation-problem. Accountability. 